\title{
Baseline neutrophil-to-lymphocyte ratio and c-reactive protein predict efficacy of treatment with bevacizumab plus paclitaxel for locally advanced or metastatic breast cancer
}

\author{
Yoshimasa Miyagawa1, Ayako Yanai ${ }^{2}$, Takehiro Yanagawa², Junichi Inatome ${ }^{2}$, \\ Chiyomi Egawa², Arisa Nishimukai', Kaori Takamoto3 ${ }^{3}$, Takashi Morimoto ${ }^{3}$, Yuichiro \\ Kikawa ${ }^{4}$, Hirofumi Suwa5 ${ }^{5}$ Tomoe Taji ${ }^{5}$, Ai Yamaguchi ${ }^{5}$, Yuki Okada ${ }^{5}$ Atsushi Sata ${ }^{1}$,

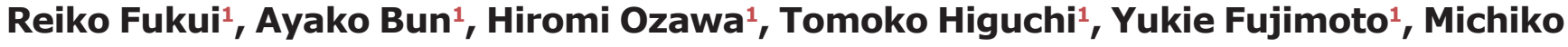 \\ Imamura $^{1}$ and Yasuo Miyoshi ${ }^{1}$ \\ ${ }^{1}$ Department of Surgery, Division of Breast and Endocrine Surgery, Hyogo College of Medicine, Nishinomiya, Hyogo 663- \\ 8501, Japan \\ ${ }^{2}$ Department of Surgery, Kansai Rosai Hospital, Amagasaki, Hyogo 660-8511, Japan \\ ${ }^{3}$ Department of Breast Surgery, Yao Municipal Hospital, Yao, Osaka 581-0069, Japan \\ ${ }^{4}$ Department of Breast Surgery, Kobe City Medical Center General Hospital, Chuo-ku, Kobe, Hyogo 650-0047, Japan \\ ${ }^{5}$ Department of Breast Surgery, Hyogo Prefectural Amagasaki General Medical Center, Amagasaki, Hyogo 660-8550, Japan \\ Correspondence to: Yasuo Miyoshi, email: ymiyoshi@hyo-med.ac.jp \\ Keywords: breast cancer; bevacizumab; neutrophil-to-lymphocyte ratio; c-reactive protein; predictive marker
}

Received: August 19, $2019 \quad$ Accepted: December 21, $2019 \quad$ Published: January 07, 2020

Copyright: Miyagawa et al. This is an open-access article distributed under the terms of the Creative Commons Attribution License 3.0 (CC BY 3.0), which permits unrestricted use, distribution, and reproduction in any medium, provided the original author and source are credited.

\section{ABSTRACT}

The effect of bevacizumab plus paclitaxel therapy on progression-free survival (PFS) is prominent; however, no overall survival (OS) benefit has been demonstrated. Our aim was to study the predictive efficacy of peripheral immune-related parameters, neutrophil-to-lymphocyte ratio (NLR), absolute lymphocyte count (ALC), and c-reactive protein (CRP) in locally advanced and metastatic breast cancers. A total of 179 patients treated with bevacizumab plus paclitaxel were recruited from three institutes in the test cohort. The cut-off values of NLR, ALC, and CRP were set at 3, $1500 / \mu \mathrm{L}$, and $1.0 \mathrm{mg} / \mathrm{dL}$, respectively, and baseline values of these factors were measured. The PFS of patients with NLR-low was significantly longer than that of patients with -high (median, 12.6 vs. 7.2 months; hazard ratio (HR), $0.48,95 \%$ confidence interval $(95 \% \mathrm{CI}), 0.31-0.73 ; p=0.0004)$. OS of patients with NLR-low was significantly better than those with-high ( 22.2 vs. 13.5 months; HR, $0.57,95 \%$ CI, $0.39-0.83 ; p=0.0032$ ). Similarly, improved PFS and OS were recognized in patients with CRP-low as compared with patients with -high (HR, 0.44, 95\% CI, 0.28-0.68; $p=0.0001$ and $\mathrm{HR}, 0.39,95 \% \mathrm{CI}, 0.26-0.61, p<0.0001$, respectively). In the validation cohort from two institutes $(n=57)$, similar significant improvements in PFS and OS were confirmed for patients with NLR-Iow $(p=0.0344$ and $p=0.0233$, respectively) and CRP-low groups ( $p<0.0001$ and $p=0.0001$, respectively). Low levels of NLR and CRP at baseline were significantly associated with improved prognosis in patients treated with bevacizumab plus paclitaxel. 


\section{INTRODUCTION}

It has been well established that angiogenesis is a critical process in progression of not only early breast cancer but also metastatic breast cancer (MBC) [1]. Vascular endothelial growth factors (VEGFs) are key players of angiogenesis, that are generated by the action of VEGFs through stimulating proliferation and migration of vascular endothelial cells [2]. Angiogenesis accompanies altered extracellular matrix and increased permeability of neovasculature, resulting in limited efficacy of chemotherapy due to decreased delivery of drugs and therapeutic agents into tumor cells [3]. Inhibition of angiogenesis with chemotherapy, therefore, is an ideal strategy for cancer treatment, not only with direct inhibition of blood supply, but also by improvement of drug delivery.

Bevacizumab, a humanized monoclonal antibody, is an inhibitor directed against VEGF-A, and blocks binding of VEGF-A to receptors including vascular endothelial growth factor receptor (VEGFR)-1, VEGFR-2, and neuropilin-1 [4]. A randomized phase III trial on 722 patients (E2100 trial) with metastatic breast cancer not previously treated with chemotherapy demonstrated improvement in progression-free survival (PFS) with the addition of bevacizumab to paclitaxel, as compared with paclitaxel alone (hazard ratio (HR), 0.60; 95\% confidence interval (CI), 0.51-0.70; $p<0.001$; median PFS, 11.8 vs. 5.9 months) [5]. In contrast to longer PFS, no improvement to overall survival (OS) of patients administered bevacizumab was reported (HR, 0.88; $p=0.16 ; 26.7$ vs. 25.2 months). Similarly, addition of $15 \mathrm{mg} / \mathrm{kg}$ bevacizumab to docetaxel treatment improved PFS (HR, 0.77; 95\% CI, 0.64-0.93; $p=0.006 ; 10.1$ vs. 8.2 months), but not OS (HR, 1.03; 95\% CI, 0.7-1.33; $p=0.85 ; 30.2$ vs. 31.9 months) as compared to treatment with docetaxel alone as first-line therapy for $\mathrm{MBC}$ in a phase III AVADO trial [6]. In a randomized phase III trial $(n=1237$ cases), which compared chemotherapy (capecitabine, taxane-based, or anthracycline-based chemotherapy) plus placebo with chemotherapy plus bevacizumab (RIBBON-1), PFS was longer for the bevacizumab group (HR, $0.69 ; 95 \%$ CI, $0.56-0.84$; $p<0.001$; median PFS, 5.7 vs. 8.6 months for capecitabine; HR, 0.64; 95\% CI, 0.52-0.80; $p<0.001$; median PFS, 8.0 vs. 9.2 months for taxane and anthracycline) [7]. However, no statistically significant differences in OS were reported between treatments with and without bevacizumab. This situation was further confirmed in a meta-analysis consisting of 2447 patients, which demonstrated no significant difference in OS (HR, 0.97; 95\% CI, 0.86-1.08; median OS, 26.7 vs. 26.4 months), although significant improvement in PFS of patients treated with bevacizumab was obtained (HR, 0.64; 95\% CI, 0.57-0.71; median PFS 9.2 vs. 6.7 months) [8]. Therefore, development of a robust biomarker that predicts benefit of bevacizumab in terms of $\mathrm{OS}$, is a critical issue in daily clinical practice.
Superior PFS induced by bevacizumab is consistently recognized, irrespective of subgroups based on clinical factors [5-7]. Since bevacizumab acts through abrogation of VEGF-A, its blood levels or factors that influence VEGF-A activity seem to be associated with bevacizumab efficacy. Therefore, circulating levels of short VEGF-A isoforms or VEGF-A receptors (neuropilin-1 and VEGFRs) in tumors or plasma are emphasized as candidates for bevacizumab biomarkers [9]. In the AVADO trial, biomarker analyses using plasma proteins, blood mRNA levels, immunohistochemistry of tumor tissue, and single-nucleotide polymorphisms of VEGF pathwayrelated genes in germline DNA were reported [10]. Of the biomarkers analyzed, VEGF-A and VEGFR-2 were identified as potential predictors for bevacizumab efficacy. On the basis of these results, VEGF-A was evaluated in a phase III trial (MERiDiAN), which compared first-line therapy for human epidermal growth factor receptor 2 (HER2)-negative MBC in 481 patients between paclitaxel plus bevacizumab and paclitaxel plus placebo groups, with prospective biomarker evaluation [11]. In this study, plasma VEGF-A (pVEGF-A) was measured and randomized according to baseline pVEGF-A concentration $(<5.05$ vs. $\geq 5.05 \mathrm{pg} / \mathrm{mL}$ ) into paclitaxel plus bevacizumab or placebo. The HRs of bevacizumab were 0.68 (99\% CI, 0.51-0.91; $p=0.0007)$ in the intent-to-treat population and $0.64(96 \%$ CI, $0.47-0.88 ; p=0.0038$ ) in the pVEGF-A high subgroup, respectively. Since the PFS by treatment-by-VEGF-A interaction was not statistically significant ( $p$ value for interaction, 0.4619), pVEGF-A was concluded to not be a predictive marker for addition of bevacizumab [12].

Recently, direct and indirect effects of VEGF on immune-related cells have been focused on. VEGF modulates the various functions of cancer immunity involving promoting regulatory $\mathrm{T}$ cells (Tregs), inhibition of dendritic cell (DC) maturation, stimulation of differentiation to tumor-associated macrophages (TAMs), and infiltration of myeloid-derived suppressor cells (MDSCs), leading to an immune suppressive microenvironment in the tumor [13]. Since bevacizumab inhibits VEGF activity, bevacizumab seems to involve amelioration of the immune microenvironment, mediated by inhibiting VEGF actions on immune-related cells, as described above. If this speculation is true, local or systemic immunity against breast cancer seems to be associated with bevacizumab efficacy. Since we demonstrated that a peripheral immune-related biomarker, neutrophil-to-lymphocyte ratio (NLR), is a predictor for eribulin [14], predictive significance of NLR and absolute lymphocyte count (ALC) for bevacizumab efficacy were investigated in patients treated with bevacizumab plus paclitaxel for locally advanced and metastatic breast cancer. In addition, a peripheral inflammatory biomarker, c-reactive protein (CRP) was also evaluated. 


\section{RESULTS}

\section{Determination of optimal cut-off values of NLR and CRP}

In order to identify the best cut-off values for NLR and CRP, we calculated variable HRs ranging from 2 to 4 for NLR and 0.1 to $2.0 \mathrm{mg} / \mathrm{dL}$ for CRP in the test cohort, as shown in the Supplementary Figure 1. The smallest $p$-values were obtained at 3 (HR, $0.48 ; 95 \% \mathrm{CI}, 0.31-0.73$; $p=0.0004$ ) for NLR and $1.0 \mathrm{mg} / \mathrm{dL}$ (HR, $0.44 ; 95 \% \mathrm{CI}$, $0.28-0.68 ; p=0.0002)$ for CRP. We used these cut-off values and classified into NLR-high $(\geq 3, n=101)$ and -low $(<3, n=78)$, and CRP-high $(\geq 1 \mathrm{mg} / \mathrm{dL}, n=62)$ and -low $(<1 \mathrm{mg} / \mathrm{dL}, n=86)$.

\section{Clinicopathological characteristics of patients treated with bevacizumab plus paclitaxel according to NLR or CRP levels}

There was no significant difference between NLRhigh and -low groups in any clinicopathological factors. More patients had disease progression in the NLR-high (62.4\%) group as compared with the NLR-low $(46.2 \%$, $p=0.083$ ) group, although the difference was not statistically significant (Table 1). Similarly, no differences involving clinicopathological factors between CRP-high and -low groups were detected (Table 1).

\section{Kaplan-Meier plots of patients according to NLR, CRP, and ALC levels for PFS or OS in the test cohort}

The PFS of patients with low levels of NLR at baseline was significantly longer than that of cases with high levels (median, 12.6 vs. 7.2 months; HR, 0.48; $95 \%$ CI, 0.31-0.73; $p=0.0004$ ) (Figure 1A). Similarly, longer OS was recognized in the NLR-low group than in the NLR-high subjects (median, 22.2 vs. 13.5 months; HR, 0.57; 95\% CI, 0.39-0.83; $p=0.0032$ ) (Figure 1B). Longer PFS (median, 11.0 vs. 6.3 months; HR, $0.44 ; 95 \%$ CI, $0.28-0.68 ; p=0.0001$ ) and OS (median, 27.2 vs. 11.3 months; HR, 0.39 ; 95\% CI, $0.26-0.61 ; p<0.0001$ ) were demonstrated in patients with low levels of CRP as compared with those with higher levels (Figure 2A, 2B). There was no significant difference in PFS between ALChigh and -low groups (median, 10.8 vs. 9.4 months; HR, 0.69 ; 95\% CI, 0.43-1.06; $p=0.0988$ ); in contrast, OS of patients with high levels of ALC was significantly better than those with low levels (median, 25.2 vs. 15.8 months; HR, 0.53 ; 95\% CI, 0.35-0.80; $p=0.0030$ ) (Figure 3A, 3B).

\section{Subgroup analyses of PFS according to clinical factors}

Consistently improved PFS in patients with NLRlow was recognized across all subgroups (Figure 4).
Favorable HRs for PFS were obtained irrespective of subtype (HR, 0.31; 95\% CI, 0.07-1.41 for luminal A; HR, 0.59; 95\% CI, 0.17-2.05 for luminal B; HR, 0.25; 95\% CI, 0.05-1.32 for HER2; HR, 0.72; 95\% CI, $0.23-$ 2.23 for triple negative (TN)), visceral disease (HR, 0.48 ; $95 \%$ CI, $0.31-0.74$ for visceral disease; HR, 0.46; 95\% CI, 0.13-1.69 for non-visceral disease), and prior number of chemotherapy treatments (HR, $0.33 ; 95 \% \mathrm{CI}$, $0.18-0.62$ for 0 or 1 prior chemotherapy; HR, 0.69 ; $95 \%$ CI, 0.34-1.40 for 2 to 4 prior chemotherapies; HR, 0.57; $95 \%$ CI, $0.18-1.80$ for 5 and more prior chemotherapies). In addition, better PFS in the NLR-low group was consistently recognized in the CRP-high (HR, 0.33; 95\% CI, 0.13-0.81) and -low (HR, 0.66; 95\% CI, 0.36-1.21) groups and ALC-high (HR, 0.43; 95\% CI, 0.16-1.11) and -low (HR, 0.50; 95\% CI, 0.28-0.88) groups.

\section{Univariable and multivariable analyses for PFS and $\mathrm{OS}$}

By univariable analysis, subtypes, the number of prior chemotherapy treatments, prior taxane use, NLR, and CRP levels were significant predictive factors for PFS (Table 2). Multivariable analysis of these factors, subtypes (HR, 2.62; 95\% CI, 1.06-6.61; $p=0.036$ for TN and HR, $4.08 ; 95 \%$ CI, $1.12-13.31 ; p=0.035$ for HER 2$)$, NLR (HR, $0.34 ; 95 \%$ CI, $0.14-0.77 ; p=0.008$ ), and CRP (HR, 0.35 ; $95 \%$ CI, $0.16-0.74 ; p=0.006$ ) were independently and significantly associated with PFS. Two subtypes (HR, 3.27; 95\% CI, $1.20-9.58 ; p=0.020$ for luminal B; and HR, 5.52; 95\% CI, 1.35-21.28; $p=0.019$ for HER2) were significantly and independently associated with OS by multivariable analysis (Table 3 ). Using multivariable analysis, we found that CRP trended toward significance (HR, 0.44, 95\% CI, 0.20-1.01; $p=0.052$ ).

\section{PFS and OS of patients divided into four groups based on NLR and CRP levels}

Kaplan-Meier analysis for PFS was performed according to four groups divided by combination of NLR and CRP levels, as shown in Figure 5. PFS of patients with NLR-low and CRP-low was highest (median, 15.0 months) and lowest in the NLR-high and CRP-high group (6.1 months, $p<0.0001$ ) (Figure 5A). Similarly, OS was significantly associated with NLR and CRP levels (NLRlow and CRP-low, 27.2 vs. NLR-high and CRP-high, 10.7 months, $p<0.0001$ ) (Figure 5B).

\section{PFS and OS of patients according to NLR, CRP, or ALC levels in the validation cohort}

We analyzed the prognostic significance of NLR, ALC, and CRP levels in the validation cohort using the cutoff values defined in the test cohort. The PFS of patients with NLR-low (median, 8.9 months) was significantly longer than those with NLR-high (median, 6.1 months; 
Table 1: Clinicopathological characteristics of patients treated with bevacizumab and paclitaxel according to neutrophil-to-lymphocyte ratio (NLR) and c-reactive protein (CRP) in the test cohort

\begin{tabular}{|c|c|c|c|c|c|c|}
\hline Characteristics & $\begin{array}{l}\text { NLR-high }^{\mathrm{a}} \\
\quad(n=101)\end{array}$ & $\begin{array}{c}\text { NLR-low }^{\mathrm{a}} \\
(n=78)\end{array}$ & $p$-value & $\begin{array}{c}\text { CRP-high }^{\mathrm{b}} \\
(n=62)\end{array}$ & $\begin{array}{c}\text { CRP-low }^{\mathrm{b}} \\
(n=86)\end{array}$ & $p$-value \\
\hline \multicolumn{7}{|l|}{ Age (year) } \\
\hline Median (Range) & $59(35-83)$ & $61(34-79)$ & $p=0.288$ & $59(34-83)$ & $61(39-79)$ & $p=0.705$ \\
\hline \multicolumn{7}{|l|}{ Menopausal status } \\
\hline Pre- & $16(15.8 \%)$ & $13(16.7 \%)$ & $p=1.000$ & $9(14.5 \%)$ & $16(18.6 \%)$ & $p=0.801$ \\
\hline Post- & $84(83.2 \%)$ & $65(83.3 \%)$ & & $53(85.5 \%)$ & $69(80.2 \%)$ & \\
\hline Unknown & $1(1.0 \%)$ & $0(0 \%)$ & & $0(0 \%)$ & $1(1.2 \%)$ & \\
\hline \multicolumn{7}{|c|}{ Estrogen receptor status } \\
\hline Positive & $75(74.3 \%)$ & $65(83.3 \%)$ & $p=0.097$ & $51(82.3 \%)$ & $69(80.2 \%)$ & $p=0.507$ \\
\hline Negative & $26(25.7 \%)$ & $12(16.0 \%)$ & & $10(16.1 \%)$ & $17(19.8 \%)$ & \\
\hline Unknown & $0(0 \%)$ & $1(1.3 \%)$ & & $1(1.6 \%)$ & $0(0 \%)$ & \\
\hline \multicolumn{7}{|c|}{ Progesterone receptor status } \\
\hline Positive & $57(56.4 \%)$ & $48(61.5 \%)$ & $p=0.089$ & $37(59.7 \%)$ & $54(62.8 \%)$ & $p=0.884$ \\
\hline Negative & $44(43.6 \%)$ & $27(34.6 \%)$ & & $24(38.7 \%)$ & $30(34.9 \%)$ & \\
\hline Unknown & $0(0 \%)$ & $3(3.9 \%)$ & & $1(1.6 \%)$ & $2(2.3 \%)$ & \\
\hline \multicolumn{7}{|l|}{ HER2 status } \\
\hline Positive & $7(6.9 \%)$ & $6(7.7 \%)$ & $p=0.343$ & $5(8.1 \%)$ & $3(3.5 \%)$ & $p=0.468$ \\
\hline Negative & $94(93.1 \%)$ & $70(89.7 \%)$ & & $56(90.3 \%)$ & $82(95.4 \%)$ & \\
\hline Unknown & $0(0 \%)$ & $2(2.6 \%)$ & & $1(1.6 \%)$ & $1(1.2 \%)$ & \\
\hline \multicolumn{7}{|l|}{ Ki67 expression levels } \\
\hline$<25 \%$ & $21(20.8 \%)$ & $12(15.4 \%)$ & $p=0.479$ & $10(16.1 \%)$ & $20(23.3 \%)$ & $p=0.565$ \\
\hline$\geq 25 \%$ & $33(32.7 \%)$ & $23(29.5 \%)$ & & $16(25.8 \%)$ & $21(24.4 \%)$ & \\
\hline Unknown & $47(46.5 \%)$ & $43(55.1 \%)$ & & $36(58.1 \%)$ & $45(52.3 \%)$ & \\
\hline \multicolumn{7}{|l|}{ Subtype ${ }^{c}$} \\
\hline Luminal A & $16(15.8 \%)$ & $10(12.8 \%)$ & $p=0.163$ & $7(11.3 \%)$ & $17(19.8 \%)$ & $p=0.407$ \\
\hline Luminal B & $16(15.8 \%)$ & $15(19.2 \%)$ & & $9(14.5 \%)$ & $13(15.1 \%)$ & \\
\hline Triple-negative & $22(21.8 \%)$ & $7(9.0 \%)$ & & $8(12.9 \%)$ & $15(17.4 \%)$ & \\
\hline HER2-positive & $7(6.9 \%)$ & $6(7.7 \%)$ & & $5(8.1 \%)$ & $3(3.5 \%)$ & \\
\hline Unknown & $40(39.6 \%)$ & $40(51.3 \%)$ & & $33(53.2 \%)$ & $38(44.2 \%)$ & \\
\hline \multicolumn{7}{|c|}{ Primary advanced or recurrence } \\
\hline Primary advanced & $38(37.6 \%)$ & $27(34.6 \%)$ & $p=0.755$ & $20(32.3 \%)$ & $33(38.4 \%)$ & $p=0.490$ \\
\hline Recurrence & $63(62.4 \%)$ & $51(65.3 \%)$ & & $42(67.7 \%)$ & $53(61.6 \%)$ & \\
\hline \multicolumn{7}{|l|}{ Metastatic sites } \\
\hline Visceral & $78(77.2 \%)$ & $66(84.6 \%)$ & $p=0.125$ & $52(83.9 \%)$ & $68(79.1 \%)$ & $p=0.807$ \\
\hline Non-visceral & $23(22.8 \%)$ & $11(14.1 \%)$ & & $10(16.1 \%)$ & $17(19.8 \%)$ & \\
\hline Unknown & $0(0 \%)$ & $1(1.3 \%)$ & & $0(0 \%)$ & $1(1.2 \%)$ & \\
\hline
\end{tabular}

Prior endocrine therapy 


$\begin{array}{lllllll}\text { Yes } & 62(61.4 \%) & 56(71.8 \%) & p=0.156 & 41(66.1 \%) & 61(70.9 \%) & p=0.591 \\ \text { No } & 39(38.6 \%) & 22(28.2 \%) & & 21(33.9 \%) & 25(29.1 \%) & \end{array}$

Number of prior chemotherapy

\begin{tabular}{|c|c|c|c|c|c|c|}
\hline 0 and 1 & $62(61.4 \%)$ & $43(55.1 \%)$ & $p=0.406$ & $38(61.3 \%)$ & $51(59.3 \%)$ & $p=0.826$ \\
\hline 2 to 4 & $27(26.7 \%)$ & $28(35.9 \%)$ & & $17(27.4 \%)$ & $27(31.4 \%)$ & \\
\hline 5 and more & $12(11.9 \%)$ & $7(9.0 \%)$ & & $7(11.3 \%)$ & $8(9.3 \%)$ & \\
\hline
\end{tabular}

Prior anthracycline therapy

$\begin{array}{lllllll}\text { Yes } & 49(48.5 \%) & 46(59.0 \%) & p=0.177 & 28(45.2 \%) & 43(50.0 \%) & p=0.618 \\ \text { No } & 52(51.5 \%) & 32(41.0 \%) & & 34(54.8 \%) & 43(50.0 \%) & \end{array}$

Prior taxane therapy

$\begin{array}{lllllll}\text { Yes } & 52(51.5 \%) & 39(50.0 \%) & p=0.881 & 30(48.4 \%) & 39(45.4 \%) & p=0.741 \\ \text { No } & 49(48.5 \%) & 39(50.0 \%) & & 32(51.6 \%) & 47(54.7 \%) & \end{array}$

Reason of treatment discontinuation

\begin{tabular}{|c|c|c|c|c|c|c|}
\hline Disease progression & $63(62.4 \%)$ & $36(46.2 \%)$ & $p=0.083$ & $41(66.1 \%)$ & $42(48.8 \%)$ & $p=0.151$ \\
\hline Adverse events & $19(18.8 \%)$ & $26(33.3 \%)$ & & $12(19.4 \%)$ & $27(31.4 \%)$ & \\
\hline Ongoing & $18(17.8 \%)$ & $15(19.2 \%)$ & & $8(12.9 \%)$ & $16(18.6 \%)$ & \\
\hline Others & $1(1.0 \%)$ & $1(1.3 \%)$ & & $1(1.6 \%)$ & $1(1.2 \%)$ & \\
\hline
\end{tabular}

ahigh: $\geq 3$, low: $<3$. ${ }^{b}$ high: $\geq 1.0 \mathrm{mg} / \mathrm{dL}$, low: $<1.0 \mathrm{mg} / \mathrm{dL}$. ${ }^{\mathrm{c} L u m i n a l} \mathrm{~A}$, estrogen receptor (ER)-positive/HER2-negative and Ki67 < 25\%; Luminal B, ER-positive/HER2-negative and Ki67 $\geq 25 \%$; TN, ER-negative/HER2-negative; HER2, HER2positive; Unknown, ER-positive/HER2-negative and Ki67 unknown.

HR, $0.47 ; 95 \%$ CI, $0.22-0.97 ; p=0.0344$ ) (Supplementary Figure 2A). As for OS, in patients with NLR-low (median, 36.8 months), OS was significantly longer than those with NLR-high (median, 18.4 months; HR, 0.43; 95\% CI, 0.20 $0.91 ; p=0.0233$ ) (Supplementary Figure 2B). Similarly, in patients with low levels of CRP, both PFS and OS were

\section{A Progression-free survival (NLR)}

$\mathrm{HR}=0.48,95 \% \mathrm{Cl}[0.31,0.73]$

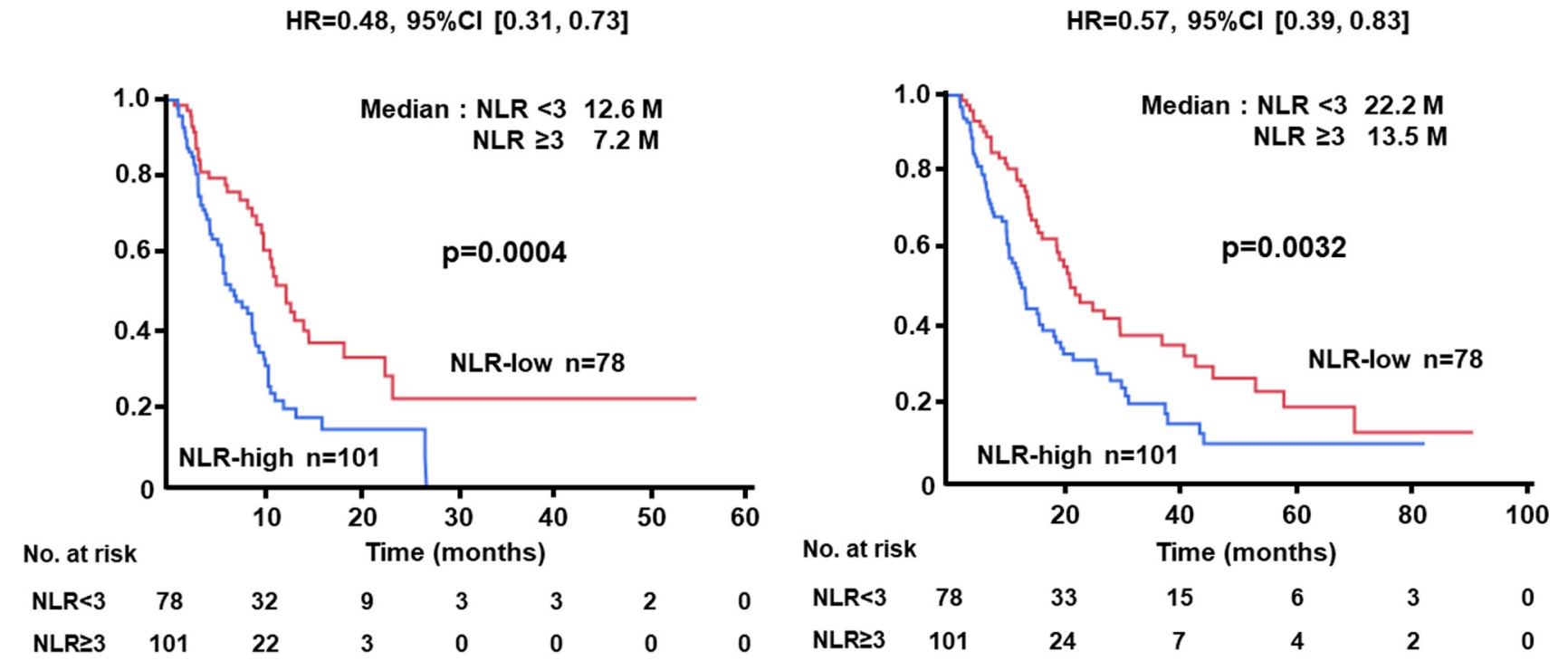

significantly longer than in patients with high levels (12.4 vs 3.5 months; HR, 0.22 ; $95 \%$ CI, $0.10-0.47 ; p<0.0001$; and 35.4 vs 7.4 months; HR, 0.24 ; $95 \%$ CI, $0.11-0.54$; $p=0.0001$, respectively) (Supplementary Figure 3). For ALC, there was a significant association between ALC levels and PFS ( $p=0.0247)$, but no significant association

Figure 1: (A) Progression-free survival (PFS) and (B) overall survival (OS) of patients grouped by neutrophil-to-lymphocyte ratio (NLR) $<3$ or $\geq 3$ groups in the test cohort. 
was found in OS ( $p=0.0841)$ (Supplementary Figure 4). When we combined NLR and CRP, the longest PFS and OS was observed in the NLR-low and CRP-low group (median 17.3 months and not reached, respectively) (Supplementary Figure 5). On the contrary, PFS and OS of patients with NLR-high and CRP-high (median 4.0 and 7.9 months, respectively) and NLR-low and CRP-high (median 3.3 and 7.4 months, respectively) were shorter.

A

$$
\text { Progression-free survival (CRP) }
$$

$\mathrm{HR}=0.44,95 \% \mathrm{Cl}[0.28,0.68]$

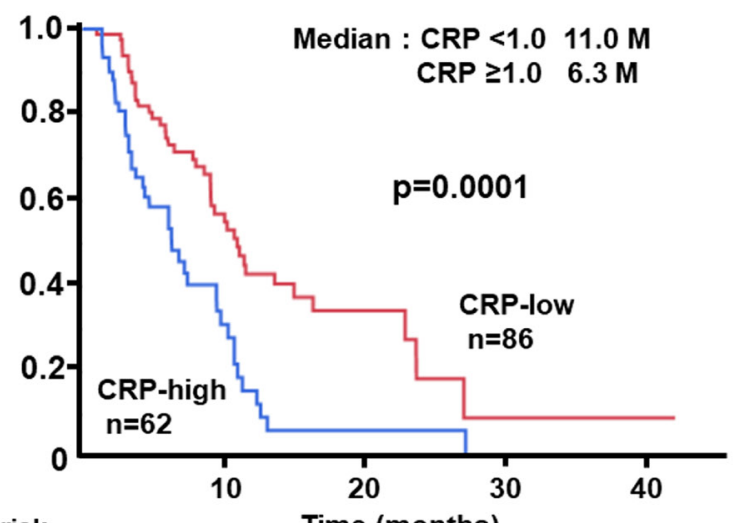

No. at risk

\begin{abstract}
Time (months)
\end{abstract}

$\begin{array}{llllll}\text { CRP }<1.0 & 86 & 32 & 7 & 2 & 2 \\ \text { CRP } \geq 1.0 & 62 & 11 & 2 & 0 & 0\end{array}$

\section{DISCUSSION}

In this study, significant improvement after bevacizumab plus paclitaxel therapy was obtained in patients with low levels of NLR and CRP at baseline in terms of OS, as well as PFS as compared with those with high levels in both the test and validation cohorts. On the contrary, consistent significant associations between ALC

B

\section{Overall survival (CRP)}

$\mathrm{HR}=0.39,95 \% \mathrm{Cl}[0.26,0.61]$

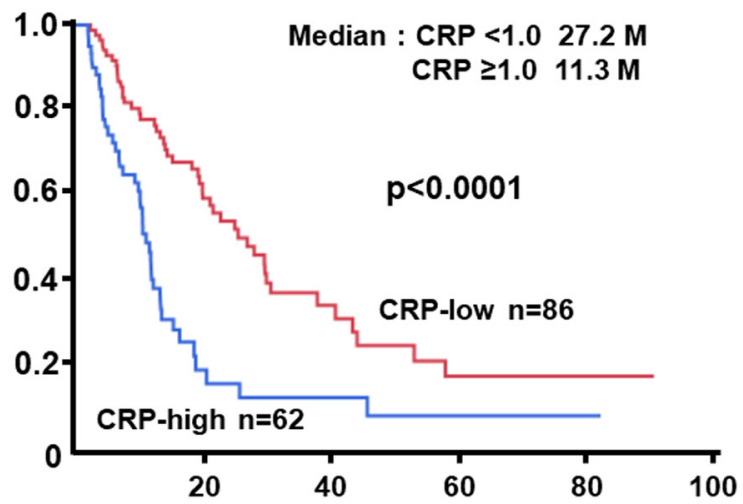

No. at risk

$\begin{array}{llccccc}\text { CRP }<1.0 & 86 & 38 & 13 & 6 & 3 & 0 \\ \text { CRP } \geq 1.0 & 62 & 7 & 4 & 2 & 2 & 0\end{array}$

Figure 2: (A) Progression-free survival (PFS) and (B) overall survival (OS) of patients grouped by c-reactive protein $(\mathrm{CRP})<1.0 \mathrm{mg} / \mathrm{dL}$ or $\geq 1.0 \mathrm{mg} / \mathrm{dL}$ groups in the test cohort.

A

$$
\text { Progression-free survival (ALC) }
$$

$\mathrm{HR}=0.69,95 \% \mathrm{Cl}[0.43,1.06]$

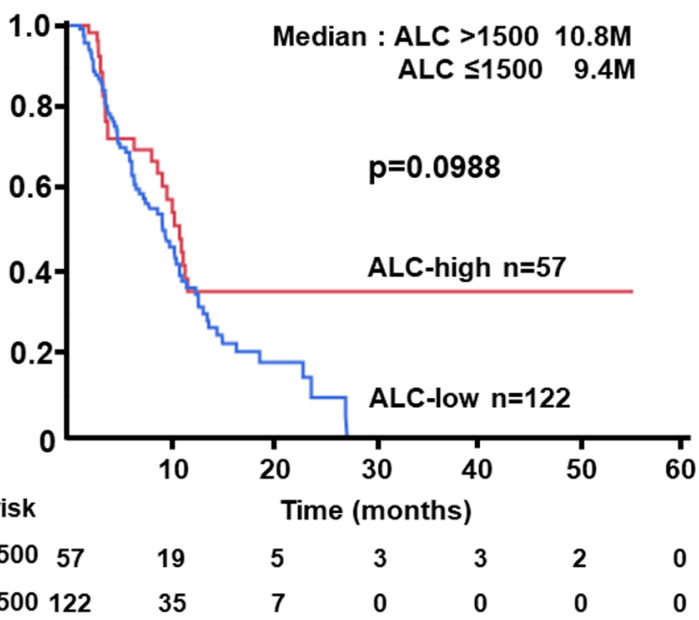

B

Overall survival (ALC)

$\mathrm{HR}=0.53,95 \% \mathrm{Cl}[0.35,0.80]$

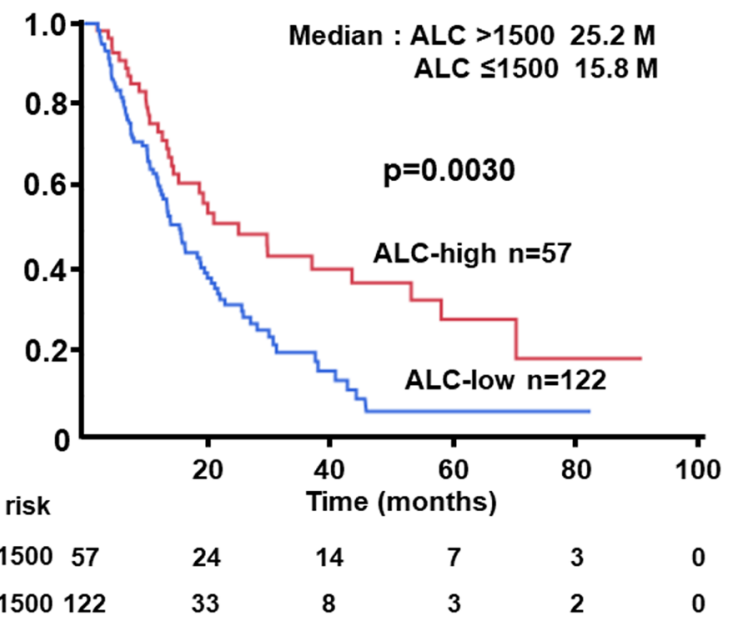

Figure 3: (A) Progression-free survival (PFS) and (B) overall survival (OS) of patients grouped by absolute lymphocyte count (ALC) $>$ $1500 / \mu \mathrm{L}$ or $\leq 1500 / \mu \mathrm{L}$ groups in the test cohort. 
and PFS, or between ALC and OS, were not obtained - neither in the test cohort nor the validation cohort. In addition, low levels of NLR and CRP were significantly and independently associated with longer PFS. These data indicated a usefulness of NLR and CRP as predictive markers of bevacizumab in addition to paclitaxel for MBC. Gampenrieder et al. constructed a DNA methylation signature ( 9 gene signature) that predicts bevacizumab efficacy in MBC (HR, 0.18; 95\% CI, 0.01-NA, $p<0.001$ for PFS; and HR, 0.24; 95\% CI, 0.07-0.38, $p<0.001$ for OS) [15]. Furthermore, predicting tools (G and GC models) for bevacizumab plus paclitaxel based on angiogenesis-related profiling have been demonstrated by Mendiola et al. [16]. These G- and GC-models identified subgroups with improved PFS (HR, 2.57 and 4.04, respectively) and $\mathrm{OS}$ (HR, 3.29 and 3.43, respectively).

In addition to these predictive models based on factors at baseline, the usefulness as a predictor of early changes to factors associated with angiogenesis or hypoxia after commencement of bevacizumab-based therapy was reported. High levels of carbonic anhydrase (CA9) after a cycle of treatment were significantly associated with longer PFS $(p<0.001)$ and OS $(p<0.001)$ as compared with low levels of CA9 increase [17]. Since CA9 is induced under hypoxic conditions by hypoxia inducible factor-1 (HIF1) [18], alteration of the microenvironment, including the hypoxic condition, by an angiogenesis inhibitor may be associated with its efficacy. In line

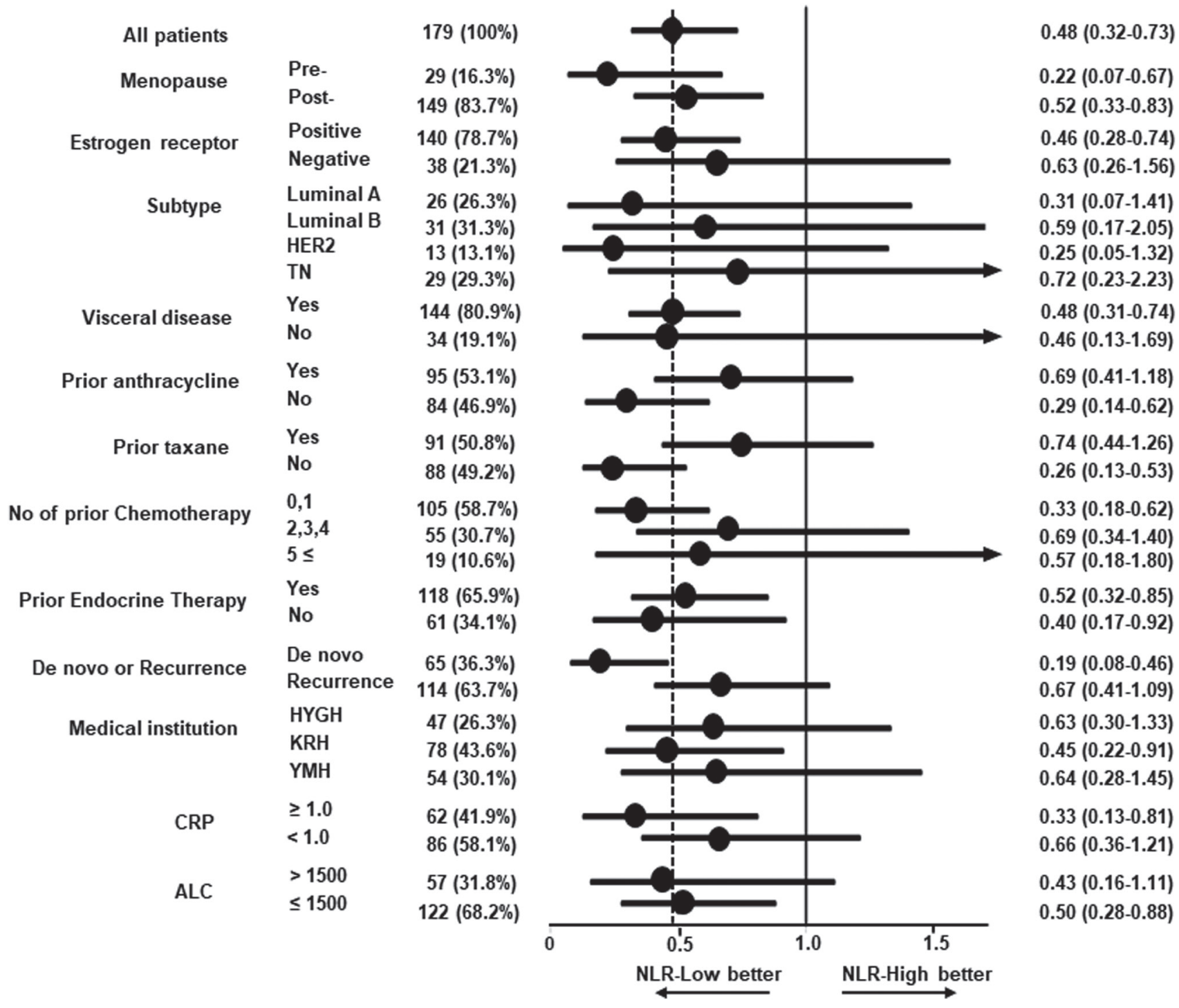

Figure 4: Forest plot for subgroup analysis of progression-free survival among patients treated with bevacizumab plus paclitaxel. Hazard ratios (HRs) and 95\% confidence intervals (CIs) in several subgroups are shown. The HR of 0.48 for all patients is shown by the dashed line. Progression-free survival was better in the low neutrophil-to-lymphocyte ratio (NLR) group across all subgroups. Subtypes: Luminal A, estrogen receptor (ER)-positive/HER2-negative and Ki67 < 25\%; Luminal B, ER-positive/HER2-negative and Ki67 $\geq 25 \%$; HER2, HER2-positive; TN, ER-negative/HER2-negative. Medical institutions: HYGH, Hyogo College of Medicine; KRN, Kansai Rosai Hospital; YMH, Yao Municipal Hospital. CRP: c-reactive protein. ALC: absolute lymphocyte count. 
Table 2: Univariable and multivariable analyses of progression-free survival for patients treated with bevacizumab and paclitaxel in the test cohort

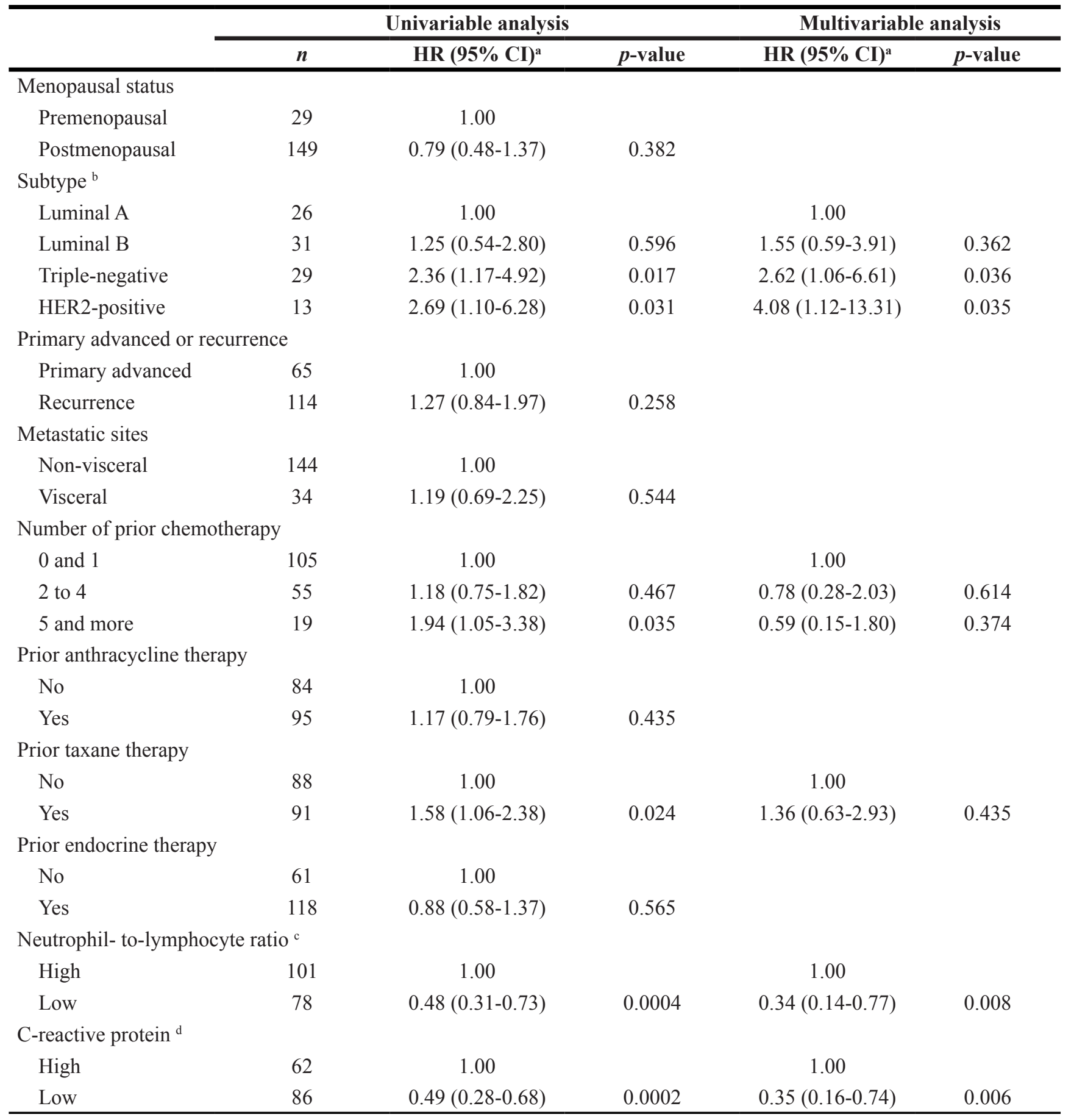

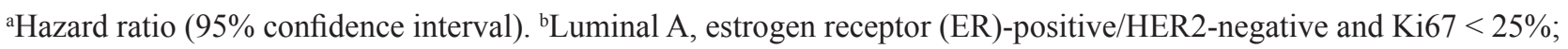
Luminal B, ER-positive/HER2-negative and Ki67 $\geq 25 \%$; TN, ER-negative/HER2-negative; HER2, HER2-positive; Unknown, ER-positive/HER2-negative and Ki67 unknow. ${ }^{c h i g h: ~} \geq 3$, low: $<3$. ${ }^{d}$ high: $\geq 1.0 \mathrm{mg} / \mathrm{dL}$, low: $<1.0 \mathrm{mg} / \mathrm{dL}$.

with this concept, vessel architectural imaging (VAI) was established for identification of patients expected to respond to anti-angiogenic therapy [19]. This technique was developed based on magnetic resonance imaging (MRI) for monitoring of vessel functions including hemodynamic status, vascular structure, and oxygen saturation $\left(\mathrm{SO}_{2}\right)$ levels. Among patients with recurrent glioblastomas treated with anti-angiogenic cediranib, treatment was effective in patients who achieved more competent microcirculation by a relative increase in vessel vortex direction in the tumor center with reduced vessel calibers accompanied by upregulation of $\mathrm{SO}_{2}$. These 
Table 3: Univariable and multivariable analyses of overall survival for patients treated with bevacizumab and paclitaxel in the test cohort

\begin{tabular}{|c|c|c|c|c|c|}
\hline & \multirow{2}{*}{$n$} & \multicolumn{2}{|c|}{ Univariable analysis } & \multicolumn{2}{|c|}{ Multivariable analysis } \\
\hline & & HR $(95 \% \text { CI })^{a}$ & $p$-value & HR $(95 \% \text { CI })^{\mathrm{a}}$ & $p$-value \\
\hline \multicolumn{6}{|l|}{ Menopausal status } \\
\hline Premenopausal & 29 & 1.00 & & & \\
\hline Postmenopausal & 149 & $0.73(0.46-1.22)$ & 0.214 & & \\
\hline \multicolumn{6}{|l|}{ Subtype ${ }^{b}$} \\
\hline Luminal A & 26 & 1.00 & & 1.00 & \\
\hline Luminal B & 31 & $2.05(0.97-4.61)$ & 0.061 & $3.27(1.20-9.58)$ & 0.020 \\
\hline Triple-negative & 29 & $2.47(1.17-5.55)$ & 0.018 & $2.30(0.86-6.60)$ & 0.097 \\
\hline HER2-positive & 13 & $3.51(1.39-8.80)$ & 0.009 & $5.52(1.35-21.28)$ & 0.019 \\
\hline \multicolumn{6}{|c|}{ Primary advanced or recurrence } \\
\hline Primary advanced & 65 & 1.00 & & 1.00 & \\
\hline Recurrence & 114 & $2.05(1.37-3.15)$ & 0.0004 & $1.35(0.54-3,23)$ & 0.517 \\
\hline \multicolumn{6}{|l|}{ Metastatic sites } \\
\hline Non-visceral & 144 & 1.00 & & & \\
\hline Visceral & 34 & $1.51(0.95-2.52)$ & 0.086 & & \\
\hline \multicolumn{6}{|c|}{ Number of prior chemotherapy } \\
\hline 0 and 1 & 105 & 1.00 & & 1.00 & \\
\hline 2 to 4 & 55 & $1.83(1.22-2.72)$ & 0.004 & $1.03(0.40-2.61)$ & 0.953 \\
\hline 5 and more & 19 & $2.40(1.33-4.10)$ & 0.005 & $2.21(0.67-6.65)$ & 0.185 \\
\hline \multicolumn{6}{|c|}{ Prior anthracycline therapy } \\
\hline No & 84 & 1.00 & & 1.00 & \\
\hline Yes & 95 & $2.04(1.39-3.05)$ & 0.0003 & $0.99(0.39-2.61)$ & 0.990 \\
\hline \multicolumn{6}{|l|}{ Prior taxane therapy } \\
\hline No & 88 & 1.00 & & 1.00 & \\
\hline Yes & 91 & $2.42(1.66-3.56)$ & $<0.0001$ & $1.73(0.64-4.83)$ & 0.284 \\
\hline \multicolumn{6}{|c|}{ Prior endocrine therapy } \\
\hline No & 61 & 1.00 & & & \\
\hline Yes & 118 & $1.39(0.94-2.12)$ & 0.100 & & \\
\hline \multicolumn{6}{|c|}{ Neutrophil- to-lymphocyte ratio ${ }^{c}$} \\
\hline High & 101 & 1.00 & & 1.00 & \\
\hline Low & 78 & $0.57(0.39-0.83)$ & 0.0033 & $0.57(0.24-1.30)$ & 0.186 \\
\hline \multicolumn{6}{|l|}{ C-reactive protein ${ }^{\mathrm{d}}$} \\
\hline High & 62 & 1.00 & & 1.00 & \\
\hline Low & 86 & $0.39(0.26-0.61)$ & $<0.0001$ & $0.44(0.20-1.01)$ & 0.052 \\
\hline
\end{tabular}

${ }^{\mathrm{a}}$ Hazard ratio (95\% confidence interval). ${ }^{\mathrm{b}}$ Luminal A, estrogen receptor (ER)-positive/HER2-negative and Ki67 < 25\%; Luminal B, ER-positive/HER2-negative and Ki67 $\geq 25 \%$; TN, ER-negative/HER2-negative; HER2, HER2-positive; Unknown, ER-positive/HER2-negative and Ki67 unknow. ${ }^{c}$ high: $\geq 3$, low: $<3$. ${ }^{\text {high }} \geq 1.0 \mathrm{mg} / \mathrm{dL}, \mathrm{low}:<1.0 \mathrm{mg} / \mathrm{dL}$.

data suggested that efficacy of angiogenesis inhibitors is mediated through not only reduction of neovasculature, but also normalization of tumor vessels and improvement in hypoxic conditions in the tumor.

It is reported that normalization of tumor vessels by inhibiting angiopoietin (Ang) 2, which is an enhancer of angiogenesis, and Tie2 activation, which induces vessel stabilization, leads to enhancement of drug delivery and production of favorable tumor microenvironments in a mouse model [20]. Interestingly, favorable changes to immune cell infiltration were observed by normalization of tumor vessels in this glioma model. Furthermore, 
targeting of tumor vessels using anti-VEGFR-2 antibody with lower doses inducing vascular normalization, but not high doses, resulted in reprograming the immune suppressive microenvironment toward the potentiation of immune active status [21]. Vascular normalization by anti-angiogenic therapy, therefore, seems to be clinically important in terms of immune reactions against cancer cells, especially mediated through T lymphocyte infiltration [22].

The precise mechanisms why NLR and CRP, but not ALC levels, are associated with PFS of patients treated with bevacizumab plus paclitaxel have yet to be resolved. According to Chen et al.'s study, high levels of NLR were significantly associated with high levels of circulating inflammatory cytokines, angiogenic cytokines, and epidermal growth factor ligands [23]. We demonstrated that the difference in median OS ( 8.7 months) between NLR-low and -high groups was higher than that in PFS (5.4 months). Similarly, increased difference in the OS (15.9 months) than in PFS (4.7 months) was recognized between CRP-low and -high groups. These data may represent a possible involvement of cancer immunity modified by bevacizumab. Since high levels of NLR were significantly associated with low levels of natural killer (NK) cell activity in healthy individuals [24] and high levels of peripheral MDSC in breast cancer patients [25], NLR seems to be a surrogate for immune status against cancer cells, at least in part. Considering the function of bevacizumab, which reduces VEGF activity in addition to vascular normalization, promotes immune reactions mediated through several factors including reduction of TAM, Tregs, or MDSCs, and maturation of DCs [13], such immune modulation leads to a favorable prognosis especially in terms of OS. Since patients with low levels of NLR or CRP had greater benefit from bevacizumab as compared with those with high levels, these markers may indicate that the microenvironment in breast cancer is likely to afford sufficient efficacy induced by bevacizumab. We failed to demonstrate consistent positive associations between ALC levels and longer PFS or OS, which may indicate a predictive significance not of ALC, but of NLR and CRP for bevacizumab efficacy.

CRP is well known as an inflammatory marker, and high levels of CRP significantly are associated with worse OS in MBC [26]. In colorectal cancer, CRP levels are significantly positively associated with VEGF-A $(r=0.23, p<0.0001)$ and Ang2 $(r=0.43, p<0.001)$ [27]. On the basis of these results, the association between CRP levels and bevacizumab efficacy may be in line with that of angiogenesis. Since there was no significant association between NLR and CRP levels (data not shown), and NLR and CRP are independent factors for PFS by multivariable analysis, we believe these markers have roles involving different mechanisms in bevacizumab's effects. The limitation of this study is that these results were obtained from retrospective real-world data consisting of several treatment lines of bevacizumab for locally advanced or MBC. Furthermore, detailed mechanisms involving NLR and CRP for predicting efficacy of bevacizumab remain unknown. Another limitation was the cut-off values of NLR and CRP. In the present study, we obtained optimal cut-off values of NLR and CRP at 3.0 and $1.0 \mathrm{mg} / \mathrm{dL}$, respectively, based on the data from the test cohort. Since the significance of these cut-off values was confirmed in the validation cohort using different automatic analyzers
A

\section{Progression-free survival according to NLR and CRP levels}

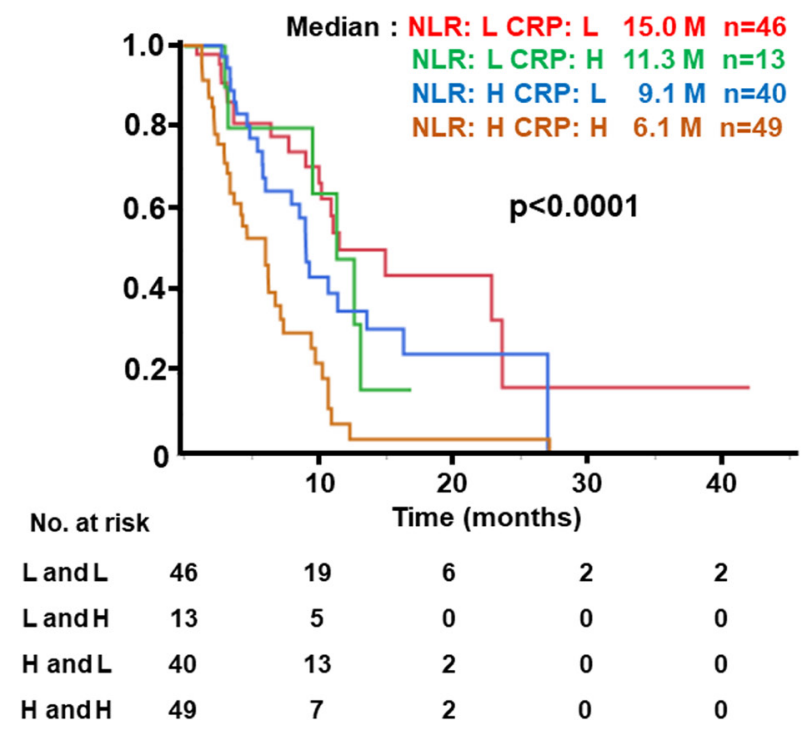

\section{B}

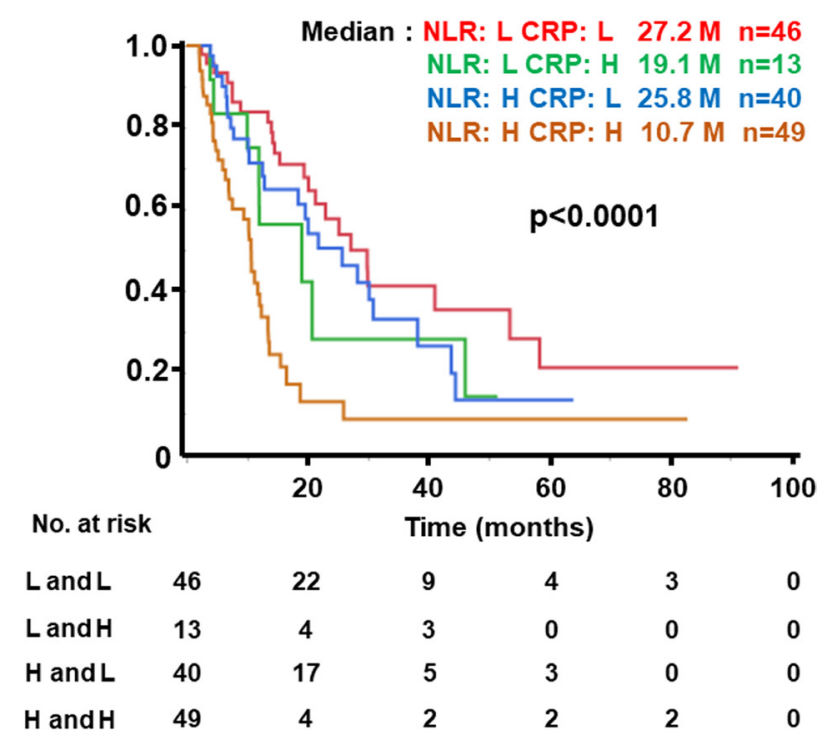

Figure 5: (A) Progression-free survival (PFS) and (B) Overall survival (OS) of patients grouped by neutrophil-to-lymphocyte ratio (NLR) and c-reactive protein (CRP) levels. NLR-high $\geq 3$, NLR-low, $<3$; CRP-high, $\geq 1.0 \mathrm{mg} / \mathrm{dL}, \mathrm{CRP}-\mathrm{low},<1.0 \mathrm{mg} / \mathrm{dL}$ in the test cohort. 
for NLR and CRP, the issue of whether these cut-off values are widely applicable in clinical settings or not still remains unknown. We need to confirm these data prospectively in future studies with larger numbers of patients.

In conclusion, we have shown that low levels of NLR and CRP are significantly associated with improved PFS and OS in advanced breast cancer treated with bevacizumab plus paclitaxel. The data obtained here seem to be useful not only for selecting patients who have benefit from bevacizumab-based therapy, but also for identifying subgroups for combination therapy with bevacizumab and immune checkpoint inhibitors. This is the first study to demonstrate the predictive utility of NLR and CRP for bevacizumab plus paclitaxel therapy in breast cancer to the best of our knowledge.

\section{MATERIALS AND METHODS}

\section{Patient eligibility}

A total of 202 patients treated with bevacizumab plus paclitaxel were retrospectively collected from three institutes (Hyogo College of Medicine, $n=60$; Kansai Rosai Hospital, $n=87$; Yao Municipal Hospital, $n=55)$ in the test cohort. Patients were excluded if they: were treated for less than one cycle $(n=18)$, had no blood data at baseline $(n=2)$, or were males with breast cancer $(\mathrm{n}=3)$. In the end, 179 patients (Hyogo College of Medicine, $n=47$; Kansai Rosai Hospital, $n=78$; Yao Municipal Hospital, $n=54$ ) were enrolled for this part of the study (Supplementary Figure 6). In the validation cohort, 63 patients were recruited from two new institutes (Kobe City Medical Center, $n=40$ and Amagasaki General Medical Center, $n=23$ ). Since six patients were excluded due to having less than one cycle of treatment, a total of 57 patients (Kobe City Medical Center, $n=35$ and Amagasaki General Medical Center, $n=22$ ) were analyzed in the validation cohort (Supplementary Figure 6). Primary breast cancer was confirmed by histology, and locally advanced state or metastases were diagnosed radiographically. HER2-positive breast cancers were eligible for treatment with bevacizumab plus paclitaxel without anti-HER2 therapy. Subtypes were classified as Luminal A, Luminal B, TN, and HER2. Accordingly, the TN $(n=29)$ and HER2 $(n=13)$ subtypes were defined as ER-negative/HER2negative and HER2-positive, respectively. ER-positive/ HER2-negative breast cancers were further divided on the basis of Ki67 expression levels as follows: Luminal A, $\operatorname{Ki} 67<25 \%, n=26$; Luminal B, Ki67 $\geq 25 \%, n=31$. In the 80 ER-positive/HER2-negative breast cancers, there was no data on Ki67 expression levels.

\section{Bevacizumab plus paclitaxel schedule and evaluation of outcome}

Bevacizumab $10 \mathrm{mg} / \mathrm{kg}$ on days 1 and 15 and paclitaxel 80 or $90 \mathrm{mg} / \mathrm{m}^{2}$ on days 1,8 , and 15 of each 28-day cycle were administered intravenously. For patients with adverse events, the dose of paclitaxel was reduced to 60 or $40 \mathrm{mg} / \mathrm{m}^{2}$ and paclitaxel was omitted when decreased neutrocyte counts or sever adverse events were noted. After the initial combination therapy, paclitaxel administration was stopped and only nine patients continued with bevacizumab. Bevacizumab with or without paclitaxel was discontinued due to disease progression and intolerable adverse events in 99 and 45 patients, respectively, and treatment was ongoing in 33 patients in the test cohort (Table 1). In the validation cohort, bevacizumab with or without paclitaxel was discontinued due to disease progression, intolerable adverse events, and other reasons in 32,13 , and three patients, respectively, and treatment was ongoing in nine patients. PFS was defined from the start of treatment until disease progression or death due to any reason, and OS was defined from the start of treatment until death due to any reason.

\section{Measurements of NLR, ALC, and CRP}

Neutrophil and lymphocyte counts were measured automatically with Sysmex hematology analyzers XN9000, XN-1000, and XE-5000 (Sysmex Corporation, Kobe, Japan) in Hyogo College of Medicine, Kansai Rosai Hospital, and Yao Municipal Hospital, respectively. The NLR of each patient was calculated by dividing the number of neutrophils by the number of lymphocytes. CRP was measured with LABOSPECT008 (Hitachi HighTechnologies Corporation, Tokyo Japan) in Hyogo College of Medicine, cobas8000 (c702) (Roche Diagnostics K. K., Japan) in Kansai Rosai Hospital, and N-assay CRP-S (NITTOBO Medical Co., Ltd, Japan) in Yao Municipal Hospital. The normal range of CRP was $\leq 0.3 \mathrm{mg} / \mathrm{dL}$. In the validation set, neutrophil and lymphocyte counts were measured automatically with Sysmex hematology analyzers XN-3100 and XN-9000 at the Kobe City Medical Center and Amagasaki General Medical Center, respectively. To measure CRP, we used a LABOSPEC 0081 (Hitachi High-Technologies Corporation) and a TBA2000FR (CANON MEDICAL SYSTEMS LTD, Tochigi, Japan) in Kobe City Medical Center and Amagasaki General Medical Center, respectively. Blood was taken on the same day as the $1^{\text {st }}$ administration before the start of treatment. This study was approved by the ethics committee of the Hyogo College of Medicine (No. 1969) and conducted in accordance with the Declaration of Helsinki. As this study collected only retrospective clinical data and offered no risk to the participants, we did not ask for their written informed consent.

\section{Statistical analysis}

Kaplan-Meier plots and log-rank tests of PFS or OS were applied for the different groups. The relationships between clinicopathological characteristics and NLR or CRP levels were calculated by Fisher's exact test or 
the Wilcoxon rank-sum test. Univariate and multivariate analyses for PFS or OS were performed using a Cox proportional-hazards model to obtain the HR and 95\% CI. Statistical significance was set at $p<0.05$ and the statistical calculations were performed using JMP Pro 11 (SAS Institute Inc., Cary, NC, USA).

\section{Abbreviations}

MBC: metastatic breast cancer; VEGF: vascular endothelial growth factor; VEGFR: vascular endothelial growth factor receptor; PFS: progression-free survival; HR: hazard ratio; CI: confidence interval; OS: overall survival; HER 2: human epidermal growth factor receptor 2; Treg: regulatory $\mathrm{T}$ cell; $\mathrm{DC}$ : dendritic cell; TAM: tumor-associated macrophage; MDSC: myeloid-derived suppressor cell; NLR: neutrophil-to-lymphocyte ratio; ALC: absolute lymphocyte count; CRP: c-reactive protein; TN: triple negative; CA9: carbonic anhydrase; HIF1: hypoxia inducible factor-1; VAI: vessel architectural imaging; MRI: magnetic resonance imaging; $\mathrm{SO}_{2}$ : oxygen saturation; Ang: angiopoietin; NK: natural killer.

\section{Author contributions}

Design of study: Ya.M.; data acquisition: Yo.M., Ay.Y., T.Y., J.I., C.E., A.N., K.T., T.M., Y.K., H.S., T.T., Ai.Y., Y.O., A.S., R.F., A.B., H.O., T.H., Y.F., M.I.; construction of data base: Yo.M., Y.F., T.H.; data analysis; Yo.M., Ya.M.; writing the original draft: Yo.M.; supervision and editing the manuscript: Ya.M. Each author revised the manuscript and approved the final version.

\section{ACKNOWLEDGMENTS}

We thank Editage (https://www.editage.jp) for English language editing.

\section{CONFLICTS OF INTEREST}

Yasuo Miyoshi received research funding and honoraria from Chugai, AstraZeneca, Eli Lilly, Pfizer, MSD, Kyowa-Kirin, Taiho, and Esai. Yuichiro Kikawa received honorarium from Eisai, Chugai, Novartis, Taiho, Pfizer, and Eli Lilly. The other authors declare that they have no conflicts of interest.

\section{FUNDING}

No funding.

\section{REFERENCES}

1. Folkman J. Tumor angiogenesis: therapeutic implications. N Engl J Med. 1971; 285:1182-1186. https://doi.org/10.1056/ NEJM197111182852108. [PubMed]
2. Hicklin DJ, Ellis LM. Role of the vascular endothelial growth factor pathway in tumor growth and angiogenesis. J Clin Oncol. 2005; 23:1011-1027. https://doi.org/10.1200/ JCO.2005.06.081. [PubMed]

3. Carmeliet P, Jain RK. Principles and mechanisms of vessel normalization for cancer and other angiogenic diseases. Nat Rev Drug Discov. 2011; 10:417-427. https://doi. org $/ 10.1038 / \mathrm{nrd} 3455$. [PubMed]

4. Ferrara N, Hillan KJ, Gerber HP, Novotny W. Discovery and development of bevacizumab, an anti-VEGF antibody for treating cancer. Nat Rev Drug Discov. 2004; 3:391-400. https://doi.org/10.1038/nrd1381. [PubMed]

5. Miller K, Wang M, Gralow J, Dickler M, Cobleigh M, Perez EA, Shenkier T, Cella D, Davidson NE. Paclitaxel plus bevacizumab versus paclitaxel alone for metastatic breast cancer. N Engl J Med. 2007; 357:2666-2676. https:// doi.org/10.1056/NEJMoa072113. [PubMed]

6. Miles DW, Chan A, Dirix LY, Cortés J, Pivot X, Tomczak P, Delozier T, Sohn JH, Provencher L, Puglisi F, Harbeck N, Steger GG, Schneeweiss A, et al. Phase III study of bevacizumab plus docetaxel compared with placebo plus docetaxel for the first-line treatment of human epidermal growth factor receptor 2-negative metastatic breast cancer. J Clin Oncol. 2010; 28:3239-3247. https://doi.org/10.1200/ JCO.2008.21.6457. [PubMed]

7. Robert NJ, Diéras V, Glaspy J, Brufsky AM, Bondarenko I, Lipatov ON, Perez EA, Yardley DA, Chan SY, Zhou X, Phan SC, O'Shaughnessy J. RIBBON-1: randomized, double-blind, placebo-controlled, phase III trial of chemotherapy with or without bevacizumab for first-line treatment of human epidermal growth factor receptor 2-negative, locally recurrent or metastatic breast cancer. J Clin Oncol. 2011; 29:1252-1260. https://doi.org/10.1200/ JCO.2010.28.0982. [PubMed]

8. Miles DW, Diéras V, Cortés J, Duenne AA, Yi J, O'Shaughnessy J. First-line bevacizumab in combination with chemotherapy for HER2-negative metastatic breast cancer: pooled and subgroup analyses of data from 2447 patients. Ann Oncol. 2013; 24:2773-2780. https://doi. org/10.1093/annonc/mdt276. [PubMed]

9. Lambrechts D, Lenz HJ, de Haas S, Carmeliet P, Scherer SJ. Markers of response for the antiangiogenic agent bevacizumab. J Clin Oncol. 2013; 31:1219-30. https://doi. org/10.1200/JCO.2012.46.2762. [PubMed]

10. Miles DW, de Haas SL, Dirix LY, Romieu G, Chan A, Pivot X, Tomczak P, Provencher L, Cortés J, Delmar PR, Scherer SJ. Biomarker results from the AVADO phase 3 trial of first-line bevacizumab plus docetaxel for HER2-negative metastatic breast cancer. Br J Cancer. 2013; 108:10521060. https://doi.org/10.1038/bjc.2013.69. [PubMed]

11. Miles D, Cameron D, Bondarenko I, Manzyuk L, Alcedo JC, Lopez RI, Im SA, Canon JL, Shparyk Y, Yardley DA, Masuda N, Ro J, Denduluri N, et al. Bevacizumab plus paclitaxel versus placebo plus paclitaxel as first-line therapy for HER2-negative metastatic breast 
cancer (MERiDiAN): A double-blind placebo-controlled randomised phase III trial with prospective biomarker evaluation. Eur J Cancer. 2017; 70:146-155. https://doi. org/10.1016/j.ejca.2016.09.024. [PubMed]

12. Miles D, Cameron D, Hilton M, Garcia J, O'Shaughnessy J. Overall survival in MERiDiAN, a double-blind placebocontrolled randomised phase III trial evaluating first-line bevacizumab plus paclitaxel for HER2-negative metastatic breast cancer. Eur J Cancer. 2018; 90:153-155. https://doi. org/10.1016/j.ejca.2017.10.018. [PubMed]

13. Ott PA, Hodi FS. Buchbinder EI. Inhibition of immune checkpoints and vascular endothelial growth factor as combination therapy for metastatic melanoma: an overview of rationale, preclinical evidence, and initial clinical data. Front Oncol. 2015; 5:202. https://doi.org/10.3389/ fonc.2015.00202. [PubMed]

14. Miyagawa Y, Araki K, Bun A, Ozawa H, Fujimoto Y, Higuchi T, Nishimukai A, Kira A, Imamura M, Takatsuka Y, Miyoshi Y. Significant association between low baseline neutrophil-to-lymphocyte ratio and improved progressionfree survival of patients with locally advanced or metastatic breast cancer treated with eribulin but not with nabpaclitaxel. Clin Breast Cancer. 2018; 18:400-409. https:// doi.org/10.1016/j.clbc.2018.03.002. [PubMed]

15. Gampenrieder SP, Rinnerthaler G, Hackl H, Pulverer W, Weinhaeusel A, Ilic S, Hufnagl C, Hauser-Kronberger C, Egle A, Risch A, Greil R. DNA methylation signatures predicting bevacizumab efficacy in metastatic breast cancer. Theranostics. 2018; 8:2278-88. https://doi.org/10.7150/ thno.23544. [PubMed]

16. Mendiola M, Martínez-Marin V, Herranz J, Heredia V, Yébenes L, Zamora P, Castelo B, Pinto Á, Miguel M, Díaz E, Gámez A, Fresno JÁ, Ramírez de Molina A, et al. Predictive value of angiogenesis-related gene profiling in patients with HER2-negative metastatic breast cancer treated with bevacizumab and weekly paclitaxel. Oncotarget. 2016; 7:24217-24227. https://doi.org/10.18632/ oncotarget.8128. [PubMed]

17. Lam SW, Nota NM, Jager A, Bos MM, van den Bosch J, van der Velden AM, Portielje JE, Honkoop AH, van Tinteren H, Boven E; ATX Trial Team. Angiogenesisand hypoxia-associated proteins as early indicators of the outcome in patients with metastatic breast cancer given first-line bevacizumab-based therapy. Clin Cancer Res. 2016; 22:1611-1620. https://doi.org/10.1158/1078-0432. CCR-15-1005. [PubMed]

18. Potter CP, Harris AL. Diagnostic, prognostic and therapeutic implications of carbonic anhydrases in cancer. Br J Cancer. 2003; 89:2-7. https://doi.org/10.1038/sj.bjc.6600936. [PubMed]

19. Emblem KE, Mouridsen K, Bjornerud A, Farrar CT, Jennings D, Borra RJ, Wen PY, Ivy P, Batchelor TT, Rosen BR, Jain RK, Sorensen AG. Vessel architectural imaging identifies cancer patient responders to anti-angiogenic therapy. Nat Med. 2013; 19:1178-1183. https://doi. org/10.1038/nm.3289. [PubMed]

20. Park JS, Kim IK, Han S, Park I, Kim C, Bae J, Oh SJ, Lee S, Kim JH, Woo DC, He Y, Augustin HG, Kim I, et al. Normalization of tumor vessels by tie2 activation and ang2 inhibition enhances drug delivery and produces a favorable tumor microenvironment. Cancer Cell. 2016; 30:953-967. https://doi.org/10.1016/j.ccell.2016.10.018. [PubMed]

21. Huang Y, Yuan J, Righi E, Kamoun WS, Ancukiewicz M, Nezivar J, Santosuosso M, Martin JD, Martin MR, Vianello F, Leblanc P, Munn LL, Huang P, et al. Vascular normalizing doses of antiangiogenic treatment reprogram the immunosuppressive tumor microenvironment and enhance immunotherapy. Proc Natl Acad Sci U S A. 2012; 109:17561-17566. https://doi.org/10.1073/ pnas.1215397109. [ PubMed]

22. Tian L, Goldstein A, Wang H, Ching Lo H, Sun Kim I, Welte T, Sheng K, Dobrolecki LE, Zhang X, Putluri N, Phung TL, Mani SA, Stossi F, et al. Mutual regulation of tumour vessel normalization and immunostimulatory reprogramming. Nature. 2017; 544:250-254. https://doi. org/10.1038/nature21724. [PubMed]

23. Chen ZY, Raghav $\mathrm{K}$, Lieu $\mathrm{CH}$, Jiang ZQ, Eng $\mathrm{C}$, Vauthey JN, Chang GJ, Qiao W, Morris J, Hong D, Hoff P, Tran H, Menter DG, et al. Cytokine profile and prognostic significance of high neutrophil-lymphocyte ratio in colorectal cancer. Br J Cancer. 2015; 112:1088-1097. https://doi.org/10.1038/bjc.2015.61. [PubMed]

24. Kim BR, Chun S, Cho D, Kim KH. Association of neutrophil-to-lymphocyte ratio and natural killer cell activity revealed by measurement of interferon-gamma levels in a healthy population. J Clin Lab Anal. 2019; 33:e22640. https://doi.org/10.1002/jcla.22640. [PubMed]

25. Gonda K, Shibata M, Ohtake T, Matsumoto Y, Tachibana K, Abe N, Ohto H, Sakurai K, Takenoshita S. Myeloid-derived suppressor cells are increased and correlated with type 2 immune responses, malnutrition, inflammation, and poor prognosis in patients with breast cancer. Oncol Lett. 2017; 14:1766-1774. https://doi.org/10.3892/ol.2017.6305. [PubMed]

26. Petekkaya I, Unlu O, Roach EC, Gecmez G, Okoh AK, Babacan T, Sarici F, Keskin O, Arslan C, Petekkaya E, Sever AR, Altundag K. Prognostic role of inflammatory biomarkers in metastatic breast cancer. J BUON. 2017; 22:614-622. [PubMed]

27. Volkova E, Willis JA, Wells JE, Robinson BA, Dachs GU, Currie MJ. Association of angiopoietin-2, C-reactive protein and markers of obesity and insulin resistance with survival outcome in colorectal cancer. $\mathrm{Br} \mathrm{J}$ Cancer. 2011; 104:51-59. https://doi.org/10.1038/sj.bjc.6606005. [PubMed] 